\title{
Thoughts on Clinical Medicine
}

Hector M Baillie, MD FRCPC

\author{
About the Author. \\ Hector M. Baillie is a Specialist in Complex Adult Medicine in Nanaimo, BC \\ Submitted: September 27, 2018. Accepted: November 14, 2018. Published: May 21, 2019. DOI: 10.22374/cjgim.v14i2.319
}

My first bedside teaching experience, in my third year of medical school, was a transformative experience. Dr. John Dagg, consultant physician at Glasgow Western Infirmary, sat 6 of us around the bed of a 68-year-old dockworker. He said, "each of you, ask him a question, and observe." Round and round we went, asking simple questions, measuring each response, interacting on a very basic level. He complained of progressive shortness of breath, a dry cough, and a sore right shoulder. We observed the nicotine staining and clubbing of his fingers, the clumsiness of his arm movements, his staccato speech, and, on close inspection, a small right pupil. Without touching him, or asking for test results, we had (collectively, and with no clinical experience) diagnosed his Pancoast tumour, Horner's syndrome, and ipsilateral cerebellar metastasis. We thanked him, rose as a group, and shuffled next door, to the Hematology ward (yes, we had specialty wards in those days). We met a 30-year-old East Indian shopkeeper, sitting up in bed, nursing a swollen right knee. Trauma? Gout? Acute OA? Infection? Reflecting on his situation, I asked about his family history, bringing the diagnostic exercise to a prompt conclusion. It was then that I knew this was the stuff of Conan Doyle, raw and astute clinical diagnostic medicine. I was hooked.

So, let me put forth some ideas of my own, loosely researched, but heartfelt. I consider myself a clinician. Despite advancing age and greying insights, I continue to practice ward medicine, but more so office medicine - where people come to see you in street clothes, with spouse or daughter in tow, for unhurried consultation. In both settings, I am afforded the privilege of taking part in someone's life-journey, whether as a listener, a counsellor, a portal to care, a dispenser of advice or physic, a diagnostician, or a healer. Often, we don't determine which one of these roles we are playing; often it's all of them. In fact, it wasn't until Mainport required I identify my work as scholar, communicator, colleague, health advocate etc. that I realized my interaction with patients could be defined in a similar way.
Modern medicine responds to modern demands. The $19^{\text {th }}$-century physician had few remedies for ailing patients, and expectations were different. "What ails him, doctor can we help his situation, and how long has he got to live?" may have been the anxious family's first questions. But the core response of a doctor to a request for help has, since the time of Hippocrates, been to listen to a report of symptoms, to examine through physical contact, and to engage in a therapeutic relationship.

In so doing, you "connect" with another human being in a time of great need. I sometimes wonder what other connections could have so much impact on life. Being airlifted from a sinking yacht, clutched from the tempest by a stranger one can never repay? Or being extricated from a mine collapse by grime-covered men with strong hands and stronger courage? Although we risk less, our impact on the individual, the family, and society, in general, can be huge.

How often, when sitting down with a patient do we say " $I$ am here to help you, time no matter? What troubles you, what are your fears and anxieties, how might I help?" In a hospital setting, when the patient has surrendered to a hospital gown, an IV, and good grief, a Foley catheter, your introduction comes as an afterthought. "Ms. Jones, is it? Sorry I'm late, such a busy day. Nurse tells me you have a pain in your chest. Is it a heavy pain spreading to your neck and left arm? Or does it catch you when you breathe in?" You've gone a long way down the proverbial path when she splutters "well, now that you mention it, it could be both..." The 8-minute encounter is well underway. Your next 14 questions are already formulated, and your clinical order set half filled out.

Is this our standard of good patient care? Does technology make you a better doctor? Or does it serve to shorten the time for personal interaction, so you can get on with the next patient? How short can an exchange be before it becomes irrelevant? How often are we pressed to expedite the flow through a congested hospital system? Or manage a long patient list? I am often asked, by an eager ER nurse, "so what do you think, and can we move 
the patient to the floor now?" I sheepishly reply "I'm sorry, I haven't had time to draft my conclusions, never mind formulate a differential diagnosis and an initial plan of management. Give me 10 minutes, and I'll let you know." And I resume my connection with the computer screen, not the nurse or the family or the soul in distress.

And in the back of my mind, I wonder "How did I handle that visit? Did she understand me? Did I allay her fears? Did communication happen, did she learn something from our interaction? Why did she look at her husband for answers, and why did he not ask more? Was it because he had a hearing aid, or because his first wife died this way?" More likely, I expose my human side "did I come out of that visit looking smart and confident?"

A good judge of character once said, "Oh, that God would gie us, the gift that we could see oursels as ithers see us." When I reflect "if this lady was my mother, would I be happy with this consultation?" I am often humbled. And why didn't the nurse recognize our mutual roles with "I think these are the acute issues, how can we help this person..."

What does 72-year-old Audrey Jones, a retired secretary and food-bank volunteer, a mother of three, and breast-cancer survivor, remarried to forgetful Dave, have left to tell you? Maybe, if you had 8 more minutes, that she heard little and understood less since the morphine shot; that Dave might manage the bills this week if only he knew Internet banking; and that she has a bladder infection but didn't want to tell a male doctor.

On the other hand, there is a practicality one cannot ignore. Time is at a premium. We depend on good training and experience. The former might be from medical school and Fellowship days, what you've read, or a colleague's warning, "Watch out for Pulmonary Embolus, it will always try to get by you!" And experience, that insight which time and adventure and misadventure and the wisdom of elders gives you. Experience shouldn't be your only teacher, of course, but it has the potential to hone greatness. The lemon-yellow pallor in the ataxic patient; the aphasic drug addict in the ER who still has both socks on, undisturbed; the failing asthma patient on $5 \mathrm{~L} / \mathrm{min}$ oxygen by mask; the tachycardic alcoholic who seems a bit pale.

Internal medicine specialists (previously "internists") have been diagnosticians, teachers, researchers and advocates for most of the last century. With the advent of scientific medicine, both in diagnosis and treatment, and with the trend to splinter medicine into subspecialties, the focus on history and examination skill may have waned. Sometimes rightly so. Who would diagnose an MI without an EKG and a stat troponin? Who would feel comfortable treating DKA without frequent labs? But does every appendicitis need a CT abdomen? Does every depressed patient need a TSH? Maybe so if you practice defensive medicine, another driver of medical science. Is this not "The Art of Medicine?"

Lastly, in what regard are diagnosticians' held, true clinicians, who take the time to see beyond the chronic abdominal pain, the confused old lady on 7 drugs, the child with another fall downstairs? Who listens in left-lateral decubitus, checks the oral cavity, or takes a sleep history? Who speaks with family, explains results in simple language, and makes sure everyone knows the plan? Do these individuals compete for research grants, and walk the corridors of academia? Not always. Are they valued as successful, or as recognized by anyone other than their patients? Not often. Are they sought out by physician-patients? Always.

Once you have tasted nectar, nothing else compares.

PS. Last year, I learned Dr. Dagg was alive and well in Glasgow, Scotland. I e-mailed him, and gratefully acknowledged my career exemplar. Now a long-retired senior, he has a keen eye for the patient perspective. 